\title{
Oxygen-induced regulation of the intracellular glutathione levels in erythrocytes
}

\author{
Bogdanova, A ; Heinicke, I ; Gassmann, M ; Heinicke, K
}

DOI: https://doi.org/10.1007/s00421-010-1354-5

Posted at the Zurich Open Repository and Archive, University of Zurich ZORA URL: https://doi.org/10.5167/uzh-28452

Journal Article

Published Version

Originally published at:

Bogdanova, A; Heinicke, I; Gassmann, M; Heinicke, K (2010). Oxygen-induced regulation of the intracellular glutathione levels in erythrocytes. European Journal of Applied Physiology, 109(3):575-576.

DOI: https://doi.org/10.1007/s00421-010-1354-5 


\title{
Oxygen-induced regulation of the intracellular glutathione levels in erythrocytes
}

\author{
Anna Bogdanova · Ilmar Heinicke • Max Gassmann • \\ Katja Heinicke
}

Accepted: 5 January 2010 / Published online: 22 January 2010

(C) Springer-Verlag 2010

\section{Dear Editor,}

We are replying to Dr. Böning's comments to our recently published paper on oxidative stress parameters at moderate altitude (Heinicke et al. 2009). Half cell redox potential for the couple reduced (GSH)-oxidized (GSSG) glutathione is widely accepted as a reliable measure of the intracellular redox state (Schafer and Buettner 2001). Alterations in the intracellular GSH levels may reflect the change in its de novo production, reduction of GSSG or total oxidized glutathione (R-SSG) to GSH as well as the shifts in its oxidation rate. Several groups, including the co-authors, have previously shown that hypoxia (in vivo and ex vivo) results in an increase in GSH content in rodent and human erythrocytes (Bogdanova et al. 2003, 2009). The question raised by Dr. Böning is on the origin of a transient increase in the GSH levels in human erythrocytes after accent to the altitude of $2,800 \mathrm{~m}$. He suggests that at least some of the hypoxia-induced increase in GSH may be explained by its liberation from deoxygenated hemoglobin $(\mathrm{Hb})$.

Communicated by Susan Ward.

A. Bogdanova $\cdot$ I. Heinicke $\cdot$ M. Gassmann $\cdot$ K. Heinicke Institute of Veterinary Physiology,

Vetsuisse Faculty and Zurich Center for Integrative Human

Physiology (ZIHP), University of Zurich, Zurich, Switzerland

I. Heinicke

Institute of Physiology,

University of Luebeck, Luebeck, Germany

K. Heinicke $(\square)$

Neuromuscular Center, Institute for Exercise and Environmental

Medicine of Presbyterian Hospital, Dallas, TX, USA

e-mail: katjaheinicke@texashealth.org
We disagree that the GSH data measured in our study are partially "artifacts", as we were using a reliable method of assessment of GSH, and the data could be reproduced a sufficient number of times, thereby allowing reliable statistical analysis. This observation is in line with the experimental data of ours and those of Dr. Böning's group (Hütler et al. 2000). The only technical difference in sample preparation between our group and that of Hütler et al. is that they used perchloric acid for $\mathrm{Hb}$ precipitation. Whereas, we have chosen a precipitation solution especially developed for erythrocytes that preserved GSH from oxidation in Hb-rich environment (Beutler 1971). Based on this technical difference, we suggest that an increase in GSH in erythrocytes subjected to deoxygenation indeed takes place. However, we are still convinced that deoxygenation decreases free radical production in erythrocytes, although it is not the case in some other tissues. Our recent data indicate that endothelial NO synthase (RBC-eNOS) is one of the major contributors to the $* \mathrm{O}_{2}$-generation, and regulation of the GSH levels in erythrocytes (Mihov et al. 2009). Its activity is $\mathrm{O}_{2}$-dependent, and deoxygenation will lead to its deactivation. In line with this observation, met-Hb levels were lower in erythrocytes equilibrated with gas mixtures containing 5-0.5\% $\mathrm{O}_{2}$ compared to that in equilibrium with $21 \% \mathrm{O}_{2}$ in L-arginine/nitrite-free solutions (Bogdanova et al. 2009). Therefore, it is rational to assume that deoxygenation leads to a decrease in oxidative load in erythrocytes.

Would GSSG assessment be a reliable marker of oxidative stress in our human in vivo experimental settings? Not necessarily. GSH levels in blood were assessed in human blood over the days during the assent. It is known that acute oxidative stress indeed causes increased GSSG levels before depletion of the GSH pool is observed. However, when accumulating in the cytosol GSSG above the threshold 
at which reduction of it to GSH becomes impossible, GSSG is actively removed from the cells and escapes its proper detection (Deneke and Fanburg 1989). Therefore, extensive chronic oxidative stress is characterized by GSH depletion and relatively low GSSG levels. For that reason, we decided that under our experimental conditions, GSSG as a marker of oxidation may be misleading. However, this parameter is reliably reflecting acute oxidative stress in cells during short-term experiments.

Dr. Böning suggests that binding-release of GSH from $\mathrm{Hb}$ could account for the changes in free GSH that we have observed. Our data are clearly insufficient to comment on this notion. Hypoxia could cause a number of changes, including modulation of activity of the pentose phosphate pathway, alterations in $\mathrm{NO}$ bioavailability, and $\mathrm{H}_{2} \mathrm{O}_{2}$ levels etc. Some of these factors could affect the rate of protein glutathionylation (Martinez-Ruiz and Lamas 2007; O'Brian and $\mathrm{Chu}$ 2005). Our recent findings also indicate that hypoxia may cause changes in glutathionylation of the $\mathrm{Na}$, K ATPase in the heart. There, the degree of $S$-glutathionylation is higher under hypoxic conditions compared to that in normoxic heart, which protects the SH-groups from irreversible oxidation (Yakushev and Bogdanova, unpublished observations).

As shown in cell-free system, $\mathrm{Hb}$ possesses the only one cysteine group that can be glutathionylated: $\beta$-Cys-93. The glutathionylated adducts are rather stable and glutathione reductase is required to catalyze de-glutathionylation. Impressively fast kinetics of the increase in GSH in erythrocytes upon deoxygenation suggests that, whatever the process involved in may be, it is almost instantaneous. Thus, glutathione reductase activity should be significantly up-regulated to afford it. Mild hypoxia triggered an increase in GSH of $12-20 \%$ in humans exposed to moderate altitude (Heinicke et al. 2009). However, further deoxygenation may cause further up-regulation of the intracellular GSH content which is much more pronounced (to about 50\%), (Bogdanova et al. 2003, 2009). One can roughly estimate the level of $\mathrm{Hb}$ glutathionylation that would be required to mediate this effect. As reported in our manuscript, the test subjects had about $5 \mu \mathrm{mol} \mathrm{GSH/g} \mathrm{Hb}$. One gram contains $15.5 \mu \mathrm{mol}$ of tetrameric $\mathrm{Hb}$ (MW $64458 \mathrm{~g} / \mathrm{mol}$ ). This implies that the ratio between GSH and $\mathrm{Hb}$ tetramer is 5 to 15.5 (approx. 1:3). In turn, this will mean a ratio of $1: 6$, between free GSH and $\beta$-Cys-93. A $20 \%$ increase in GSH content means liberation of $1.25 \mu \mathrm{mol} \mathrm{GSH}$ from $\beta$-Cys- 93 (4\%), whereas a $50 \%$ increase implies that $2.5 \mu \mathrm{mol}(8 \%)$ of $\beta$-Cys-93 is de-glutathionylated. Maximal amount of glutathionylated hemoglobin $(\mathrm{G}-\mathrm{Hb})$ reported in intact erythrocytes, after treatment with $2,2^{\prime}$-dithiodipyridine, was $25 \%$ (Garel et al. 1986). The degree of $S$-glutathionylation of
$\mathrm{Hb}$ in circulating human erythrocytes has never been assessed, but is supposed to be much lower than that achieved after chemical facilitation of this SH group modification. Therefore, we can only speculate whether this process may contribute to an increase in GSH levels we observe in hypoxic cells. To prove if GSH release from the $\beta$-Cys-93 indeed occurs under hypoxic conditions one could use the transgenic mouse strain lacking $\beta$-Cys-93 (Isbell et al. 2008), or apply inhibitors of glutathione reductase prior to hypoxic treatment of erythrocytes ex vivo. As long as these experiments are not performed, all discussions on the possible involvement of hemoglobin in GSH release will remain speculative.

\section{References}

Beutler E (1971) Red cell metabolism. A manual of biochemical methods. Grune \& Stratton, New York

Bogdanova AY, Ogunshola OO, Bauer C, Gassmann M (2003) Pivotal role of reduced glutathione in oxygen-induced regulation of the $\mathrm{Na}(+) / \mathrm{K}(+)$ pump in mouse erythrocyte membranes. J Membr Biol 195:33-42

Bogdanova A, Berenbrink M, Nikinmaa M (2009) Oxygen-dependent ion transport in erythrocytes. Acta Physiologica (Oxford, England) 195:305-319

Deneke SM, Fanburg BL (1989) Regulation of cellular glutathione. Am J Physiol 257:L163-L173

Garel MC, Domenget C, Caburi-Martin J, Prehu C, Galacteros F, Beuzard Y (1986) Covalent binding of glutathione to hemoglobin. I. Inhibition of hemoglobin S polymerization. J Biol Chem 261:14704-14709

Heinicke I, Boehler A, Rechsteiner T, Bogdanova A, Jelkmann W, Hofer M, Rawlings P, Araneda OF, Behn C, Gassmann M, Heinicke K (2009) Moderate altitude but not additional endurance training increases markers of oxidative stress in exhaled breath condensate. Eur J Appl Physiol 106:599-604

Hütler M, Pollmann C, Beneke R, Leithauser R, Boning D (2000) Measurable amount of glutathione in blood is influenced by oxygen saturation of hemoglobin. Clin Chim Acta Int J Clin Chem 301:213-217

Isbell TS, Sun CW, Wu LC, Teng X, Vitturi DA, Branch BG, Kevil CG, Peng N, Wyss JM, Ambalavanan N, Schwiebert L, Ren J, Pawlik KM, Renfrow MB, Patel RP, Townes TM (2008) SNOhemoglobin is not essential for red blood cell-dependent hypoxic vasodilation. Nat Med 14:773-777

Martinez-Ruiz A, Lamas S (2007) Signalling by NO-induced protein $S$-nitrosylation and $S$-glutathionylation: convergences and divergences. Cardiovasc Res 75:220-228

Mihov D, Vogel J, Gassmann M, Bogdanova A (2009) Erythropoietin activates nitric oxide synthase in murine erythrocytes. Am J Physiol Cell Physiol 297:C378-C388

O'Brian CA, Chu F (2005) Post-translational disulfide modifications in cell signaling - role of inter-protein, intra-protein, $S$-glutathionyl, and $S$-cysteaminyl disulfide modifications in signal transmission. Free Radic Res 39:471-480

Schafer FQ, Buettner GR (2001) Redox environment of the cell as viewed through the redox state of the glutathione disulfide/glutathione couple. Free Radic Biol Med 30:1191-1212 